
terms of the Creative Commons Attribution-NonCommercial-ShareAlike licence (http://creativecommons.org/licenses/by-nc-sa/4.0/), which permits non-commercial re-use, distribution, and reproduction in any medium, provided the same Creative Commons licence is included and the original work is properly cited. The written permission of Cambridge University Press must be obtained for commercial re-use.

\title{
Letter
}

\section{How Parties React to Voter Transitions}

\author{
TARIK ABOU-CHADI University of Zurich \\ LUKAS F. STOETZER Humboldt University of Berlin
}

\begin{abstract}
7 his letter investigates how voter transitions between parties affect parties' policy positioning. While a growing literature investigates the role of election results as signals for parties' policy adaption, it has mostly focused on vote changes of individual parties. However, parties do not know only whether they have won or lost in an election; they also have detailed information on which parties they won votes from and which parties they lost votes to. We make two arguments about how voter transitions should affect the strategic policy choices of political parties. First, when a party has lost votes to another party it will adapt its policy positions toward that party. Second, parties that have overall lost more votes become more likely to adapt their positions. Making use of a data set on individual voter transitions and party positions we can demonstrate that voter transitions indeed affect parties' competitive behavior.
\end{abstract}

$\mathbf{O}$ $\mathrm{n}$ the evening of September 24, 2017, the German chancellor Angela Merkel steps in front of the cameras to comment on the result of the German federal election. Her party is predicted to have lost nearly 10 percentage points compared with the election in 2013. One million voters have switched from her CDU/CSU to the populist radical right AfD. In her first statement on that evening, Angela Merkel immediately addresses this issue. "We want to win voters back from the AfD," she says, "We want to offer solutions to their problems by addressing their grievances and fears." 1

The behavior of the German chancellor describes a common pattern in multiparty democracies: politicians refer to exchanges of voters between parties when explaining or justifying their behavior. We refer to these patterns of vote switching between parties as

Tarik Abou-Chadi (D), Assistant Professor at the Department of Political Science, University of Zurich, tarik.abou-chadi@uzh.ch.

Lukas F. Stoetzer (iD), Post-doc at the Cluster of Excellence Contestations of the Liberal Script (SCRIPTS), Humboldt University of Berlin, Germany, lukas.stoetzer@hu-berlin.de.

A previous version of this article was presented at the Annual Meeting of the American Political Science Association 2017, the Annual Meeting of the German Political Science Association 2018, the Workshop "Party competition in European Multi-Level Systems" at the Mannheimer Zentrum für Europäische Sozialforschung (MZES) in 2017, and an internal seminar at the Department of Political Science at the University of Zurich. We want to thank the discussants Herber Kitschelt, Thomas Meyer, Daniel Bischof, Alejandro Ecker, and three anonymous reviewers for their valuable suggestions and helpful feedback. Further, we personally thank Matthias Orlowski for earlier work on the project.

Replication files are available at the American Political Science Review Dataverse: https://doi.org/10.7910/DVN/HULLNG.

Received: April 18, 2019; revised: November 15, 2019; accepted: February 25, 2020.

${ }^{1}$ https://www.welt.de/politik/deutschland/article168995615/Vollmuttiviert-sieht-anders-aus.html. voter transitions. For political science scholars references such as Angela Merkel's should be noteworthy because they point to a crucial aspect of modern democracy: politicians' responsiveness to electoral demand. As we lay out in this letter, it is striking that this pattern has not received more attention.

We make two arguments about the relationship between voter transitions and party behavior that describe the where and when of parties' policy position adjustments in reaction to voter transitions. First, parties will adjust their position and move toward the party that they have lost votes to. Having lost votes to a party provides parties with a signal of a potentially better position. Second, in order to understand parties' policy adaptions in response to voter transitions, we need to take into account their overall gains and losses. When a party has overall gained votes, its incentive to adjust its position is low-even to a party that it has lost votes to. However, parties that have overall lost votes will be more likely to shift their position toward a party that they have lost votes to.

We create a data set of vote switching based on vote recall questions in national election studies to test these hypotheses. Using this information, we estimate spatial autoregressive models and specify the weighting matrix based on voter transitions. This allows us to test how parties adapt their positions to parties that they have lost votes to and how this is conditional on parties' own overall electoral performance. We measure these shifts based on policy position measures from the Manifesto Project and show that parties, especially in the context of higher overall losses, move toward other parties that they have lost votes to in the last election. We can also demonstrate that these findings are robust when controlling for shifts in public opinion and adaption to ideological neighbors, and they are more pronounced for mainstream than for niche parties. 
These findings constitute an important contribution to the literature on political parties and democratic representation because they demonstrate empirically that parties indeed react to election results, thus confirming a central idea of theories about parties' behavioral decision rules. When parties use elections as signals to adjust their behavior, however, they do not necessarily rely on changes in vote shares alone, but make use of information about vote switching. Introducing voter transitions as a determinant of party behavior will also allow for more nuanced analyses of the strategic behavior of political parties and their competition for different segments of the electorate. Our findings have equally important implications for research beyond party politics because they can shed light on the strategic incentives of political parties in their role in policy making and democratic responsiveness.

\section{VOTER TRANSITIONS AND PARTY BEHAVIOR}

Political science has seen an increase in studies that investigate parties' policy positions not through spatial equilibrium solutions, but based on behavioral decision rules that structure parties' strategic behavior. Because these theories assume that parties do not possess perfect information about the median voter position, signals about potentially vote-maximizing strategies become critical to understanding party behavior. Based on this reasoning, these studies postulate that election results should play a central role in signaling electoral preferences and should thus affect parties' policy positions (e.g., Budge 1994; Laver 2005). However, most studies only find limited evidence for this relationship (Adams et al. 2004; Ezrow et al. 2011). Somer-Topcu (2009) is among the few studies to find such an effect, and even here it is comparatively weak and declining over time.

A potential reason for this discrepancy lies in the fact that these empirical studies rely solely on one piece of information that parties can process: changes in their own vote shares. However, election results are necessarily interdependent. Therefore, while parties may not have precise information about the median voter position and the distribution of voter preference, they are aware of more than their own vote shares. Parties do not just observe whether they won or lost votes themselves; they give equal attention to how other parties performed. More precisely, they know which other parties they have lost voters to and which parties they have received voters from. Vote switching should thus play a fundamental role in structuring parties' strategic position taking. However, we are not aware of any comparative empirical studies of multiparty competition that include information about vote switching when analyzing parties' dynamic behavior. So how should we expect these voter transitions between parties to affect their strategic policy position choices?

A first question that we need to answer in this regard is where parties will move in reaction to observing voter transitions between their party and others. Theoretical work on the strategic behavior of vote-seeking political parties describes how parties can improve their electoral results by learning from other parties and emulating their behavior (Fowler and Laver 2008; Laver 2005). Voter transitions should provide a powerful signal to parties that want to learn from other parties' behavior. Böhmelt et al. (2016), for example, demonstrate how parties learn from foreign incumbents and adjust their behavior accordingly. In the domestic arena, parties should have the biggest incentive to emulate the behavior of parties that have demonstrated that they are better adjusted to the specific competitive environment, that is, parties they have lost votes to.

Crucially, within multiparty competition, parties of course exchange votes with several other parties. Therefore, two factors will operate to determine parties' incentives to move in one direction or the other: the ideological location of the parties that it has lost votes to (gained from) and the concentration or dispersion of vote loss (gains). We expect parties to weigh the amount of votes they have lost or gained to their left or right against each other. Parties will have the strongest incentive to move into one direction if they have lost all votes either to the left or right. Incentives to adjust their position in one direction will decrease with the degree of dispersion of gains and losses over both sides. In addition, the more concentrated a party's losses are to one other party, the bigger is the signal this party receives. Therefore, parties should respond most strongly to the parties that they have lost the most votes to. Our first hypothesis thus states the following:

H1: The more votes a party has lost to another party the more it will adapt to this party's position.

However, parties will not always have the same incentives to adjust their position to a party they have lost votes to. If a party has gained more votes than it has lost overall, there is no reason for the party to adjust its position and risk giving up this overall beneficial position. Generally, parties may be reluctant to make bigger shifts in their policy positions, as these might cause factions within the party or tarnish the party's ideological brand (Somer-Topcu 2009). Adams et al. (2004), for example, demonstrate that parties only change their positions when public opinion moves away from them. Therefore, parties that have overall won votes at the previous election will not be willing to make big adjustments and will thus be less likely to adjust their position to a party that they have lost votes to. In contrast, when parties have lost votes they will become more likely to engage in novel strategies and will thus more strongly adjust their position to parties that they have lost votes to. This leads us to our second hypothesis:

$\mathrm{H} 2$ : The more a party has overall lost votes at the previous election the more it will adapt its position to a party that it has lost votes to. 


\section{RESEARCH DESIGN}

We test our argument by using a data set that combines parties' policy positions derived from election manifestos with information on voter transitions from individual-level post-election survey data. It contains the positions of 72 parties that competed in 84 elections in 10 Western European countries between 1970 and 2017. The countries included are Austria, Denmark, Finland, Germany, Great Britain, Ireland, the Netherlands, Norway, Spain, and Sweden. For an overview of the elections and parties included in our study please refer to the supplementary material A. Our measure of the positions of political parties is based on data from the manifesto project's left-right (RILE) index (Volkens et al. 2017). The RILE index combines the fraction of quasi sentences in a manifesto that is devoted to leftist issues with that devoted to rightist issues into a single index ranging from - 100 to 100 , with higher values indicating more rightist positions.

To analyze how parties react to voter transitions we explain the position of a party as a function of all other parties' positions. The focus on positions helps us to evaluate whether party $\mathrm{A}$ is influenced by other parties' policy platforms. To understand these influences in terms of policy adaptations, it is further important to consider the previous position of party A. This helps us to understand what position party A would have offered had it not tried to adapt to other parties' policy positions. While there are multiple parties B that could have an influence on party A, our argument specifies that party A should especially react to parties that it lost votes to. We consider this information by weighting the position of other parties with the net loss of party A to those parties in the previous election. This implies that parties to which party A lost a lot of votes are allowed to have stronger influence on party A's new position. Our second argument then specifies that only parties that overall lost votes in the last election will follow this logic, and we take this into account by evaluating the relationship separately for parties that lost a large share of votes and parties that only lost a small amount or gained votes. Our modeling strategy follows previous studies of adaptive party behavior that employ spatial econometric models to estimate the interdependence of party positioning (Böhmelt et al. 2016; Williams and Whitten 2015). We follow this approach here and represent the different components as a dynamic spatial lag model, which we describe in more detail in the supplementary material B. The key of the modeling strategy is to specify a weighting matrix $\mathbf{W}$ that represents which parties a party is hypothesized to adapt to.

To specify the weight matrix $\mathbf{W}$ we use information from national election studies and the Comparative Study of Electoral Systems that include questions about respondents' vote choice in the last general election and vote-recall questions regarding the election preceding it. The basic transition matrices that contain estimates for vote swings among any pair of parties are simple cross-tabulations of these two items, taking into account the appropriate sampling weights. ${ }^{2}$ To test our hypothesis, we only include the negative net transfers in the weight matrix, which makes the values directly interpretable as the net percentage of previous voters who decided to vote for another party. In the supplementary material B, we give a detailed description and examples of how we measure and specify $\mathbf{W}$. We also validate our survey measurement based on the overall vote losses and find a high correlation between the survey measure and the actual changes between elections (See the supplementary material B.4).

For our main analysis, we further create a measurement of overall vote change. We use vote change relative to the size of the party because we expect that changes in vote shares have different consequences for smaller or larger parties. For example, a 1\% percentage point loss is more important for a small party with $5 \%$ at the last election than for a large party that gained $35 \%$. To take this into consideration, we create a measurement of vote change relative to the size of the party. We divide the vote change in the previous election by the sum of the last two results. This measurement ranges from -1 (lost all votes) to +1 (won all votes). In addition, we follow Adams and Somer-Topcu (2009) and control for the average shift of all parties in a system at the previous election. We also control for time-constant and country-specific influences such as the electoral system by using country fixed effects. Our effects can thus be interpreted as deviations from average position within a country over the period under study. Our findings remain substantially the same if we do not include the control variables.

\section{RESULTS}

We estimate two models to test our hypotheses. In a first specification, we include only the spatial lag, with the weight matrix multiplied with the left-right position of all other parties. The effect of this determines whether parties react positively to the platform of another party they lost votes to. Model two tests our second hypothesis that this adaptation is particularly strong among parties with increasing overall vote loss in the past election. As we would not necessarily expect the conditioning to be linearly increasing in vote loss, here we include a dichotomized interaction term that compares the effect among the 33\% lowest and 66\% highest values. ${ }^{3}$ The respective cutoff value corresponds to a relative vote loss of $5.9 \%$ of their vote. Among all parties that lost votes, $60 \%$ lost more than this share of their vote.

\footnotetext{
${ }^{2}$ In our calculations we do not include vote losses to non-voters or very small parties, as we do not have clear expectations how this should influence positions.

${ }^{3}$ The results are substantially the same when using a linear interaction term.
} 
TABLE 1. The Reaction of Parties to Voter Transitions

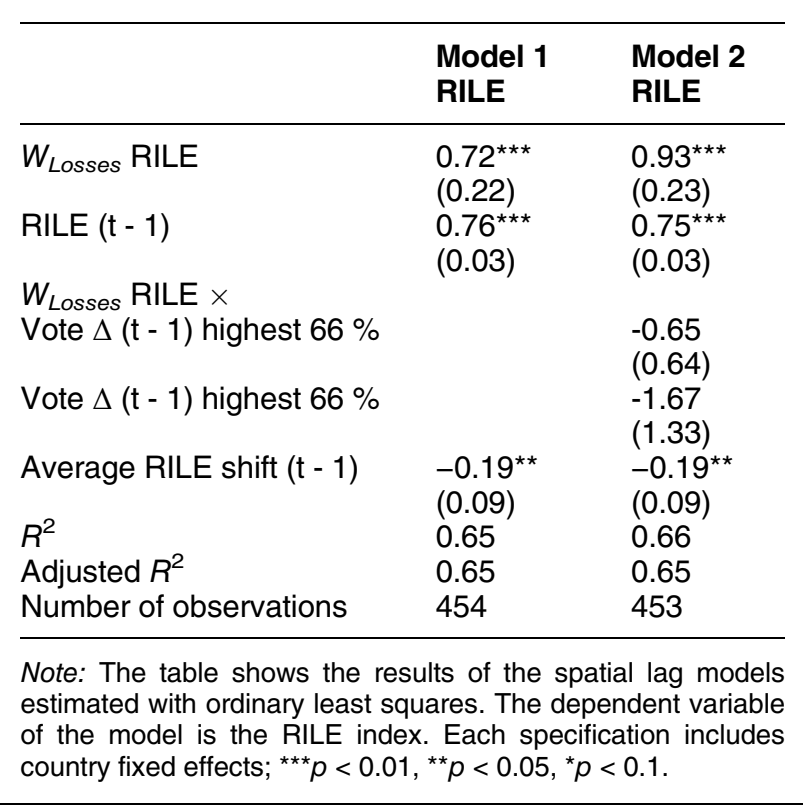

The results in Table 1 support the argument that parties adapt their policy positions to parties they have lost voters to. Model 1 shows that there is a positive effect of the spatial lag on a party's position (0.72). This implies that if party A lost votes to party B, party B's position will have a positive influence on party A's position in the upcoming election. While this influence is statistically significant, the substantive impact of this is relatively difficult to comprehend from the estimates themselves. Consider a simplified example in which party $\mathrm{A}$ has a relatively strong net loss of $20 \%$ to party B, which means that party A lost $20 \%$ of their previous vote share to party B. Suppose that Party B's platform for the upcoming election is at 25 on the RILE index and Party A's position in the previous election was at 0 . A difference of 25 points on the RILE index amounts to more or less the difference between the Labour and Conservative Party in the 2010 UK election. In this case, the marginal adaption of Party $A$ to party $\mathrm{B}$ is 3.6 on the rile scale. ${ }^{4}$ Within multiparty competition, Party A can of course simultaneously lose votes to multiple parties, for example, Party B and Party C. Here the adaption rates can cancel each other out if the other parties fall on opposite sides of Party A (say Party B at 25 and Party C at -25) and Party A lost the same share of votes to both. But multiparty competition can also magnify the effect if both party $B$ and $\mathrm{C}$ are on the same side, which would give a marginal

\footnotetext{
${ }^{4}$ The marginal rate of adaption is calculated as a change of Party A's position with changes in Party B's position times Party B's position and thereby highlights how strongly Party A adapts to Party B. We describe the quantity of interest formally in the supplementary material.
}

adaption rate toward $\mathrm{B}$ and $\mathrm{C}$ of 7.6 points on the RILE index.

The marginal effect of how parties react to the position of other parties they have lost votes to is moderated by the overall vote loss at the previous election. As we have argued in hypothesis 2, parties will require strong signals in terms of overall loss to adapt to another party's position. Model 2 shows that the magnitude of the effect increases when we condition it on the relative vote change at the preceding election. ${ }^{5}$ The direct effect in this model is the effect among the lowest $33 \%$ of parties, that is, parties that lost more than $5.9 \%$ in the last election. Compared with the direct effect in Model 1, the size of the effect with 0.93 is substantially larger. In addition, among the highest $66 \%$ the negative interaction indicates that for this group the spatial lag has no positive effect. Therefore, parties that overall lose less strongly (or win votes) do not react to losing votes to other parties. In line with our expectations, only parties with strong incentives to shift their position strategically adjust their policy profile in accordance with parties that they have lost votes to.

The estimates obtained from the interaction effect model further highlight that this adaptation can be quite substantial. Figure 1 illustrates the example discussed above for the estimates from model 2. The plot shows the marginal rate of adaption of party $A$ in the direction of party B for different scenarios. It highlights that the net vote loss from Party A to Party B will affect Party A's positioning, but only when there is a strong total vote loss in the proceeding election (more than $5.8 \%$ of its previous votes share). The right panels show that (in this case) if party A lost $5 \%$ of its previous votes to Party B, Party A will adapt its position in direction of Party B with 1.2 scale points. With $15 \%$ vote loss, the adaption will be around 3.5 . With $40 \%$ of net vote loss, the position will be at 8.2 and even closer to Party B. For a case where a party did not lose much in the last election, the left panel shows that then Party A does not adapt to Party B's position. These examples illustrate the consequences for a two-party case with two parties that are quite close together in the political space. We exemplify the case for multiparty competition in the supplementary material C.2.

We conduct a set of robustness checks. First, we analyze whether two alternative covariates could explain our findings. The results are robust when (a) controlling for shifts in public opinion and (b) when controlling for the idea that parties might simply react to parties that are ideologically close. In addition, we consider two modeling and measurement issues that could be relevant for our findings. The results are robust when using the log-RILE left-right position (Lowe et al., 2011) and still hold when including party-fixed effects. We further analyze differences between mainstream parties and niche parties and find that our results are more emphasized for mainstream

\footnotetext{
${ }^{5}$ Supplementary material C.1 contains a plot with the marginal effects.
} 


\section{FIGURE 1. Example of How Parties Are Expected to Adapt Position to Competitors}

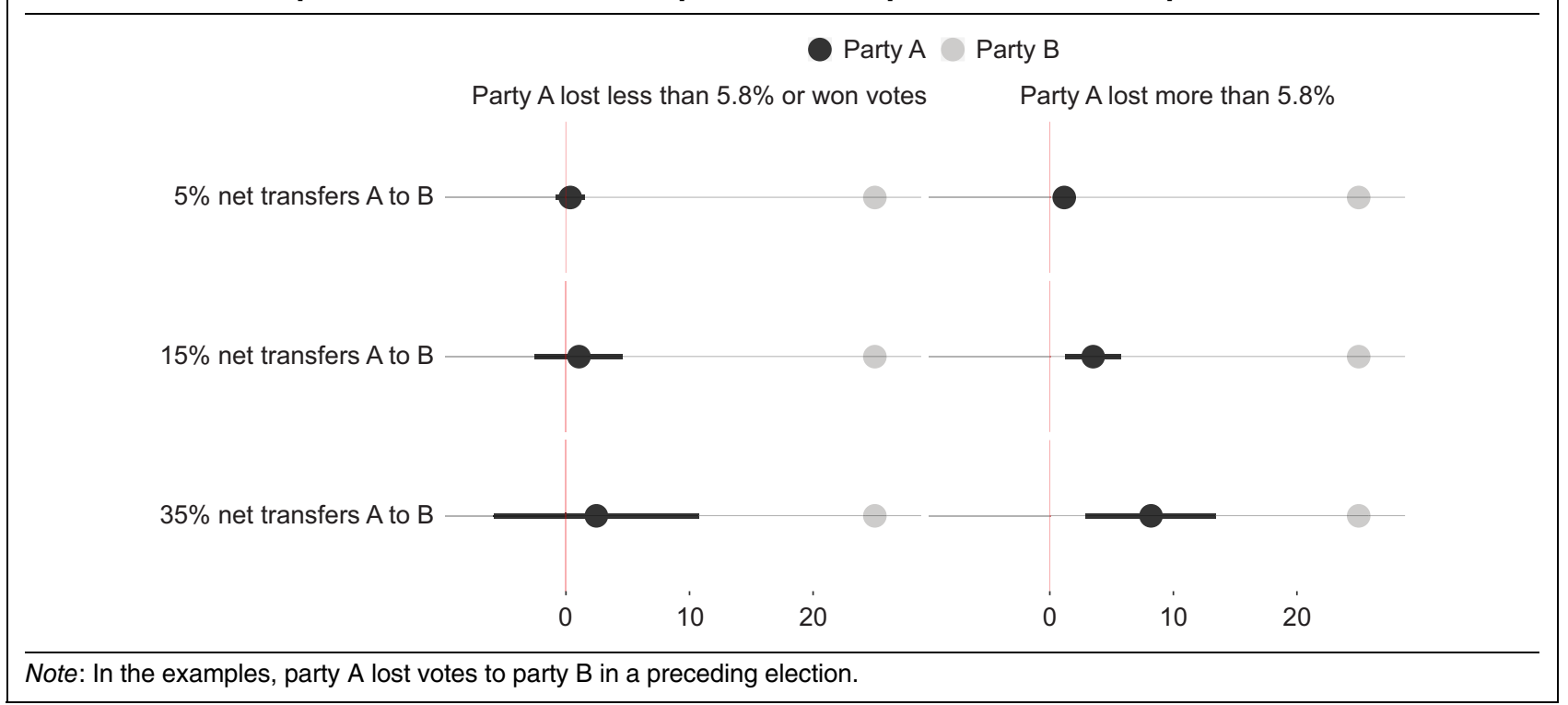

parties. All of these results are elaborated in more detail in the supplementary material D.

\section{CONCLUSION}

In this letter, we demonstrate how parties strategically adapt their policy positions in response to voter transitions. We can show that parties that have lost more votes to another party more strongly adjust their policy position toward this party. Especially when they have lost a lot of votes in an election, parties adjust their position to the party they have lost votes to. Substantively, the effects of voter transitions on party behavior go far beyond the effects usually found when investigating the effects of election results on party positioning.

We should emphasize that within this letter we do not intend to provide a full model of party competition. We focus on one crucial aspect: how parties receive information from election results and adjust their position in accordance. Our letter thus contributes to a literature trying to uncover behavioral decision rules for political parties. In addition to the mechanism that we have uncovered, other findings about the strategic behavior of political parties in the competitive space will still be relevant. Therefore, additional rules can be used to formulate more specific expectations, for example, that parties rarely leapfrog. Analyzing heterogeneous responses of parties should also be a fruitful way forward.

We provide a first comparative test of the effect of voter transitions on the competitive behavior of political parties. For observers of real world political parties, it is certainly not surprising that voter transitions matter for parties' policy positions. It is thus all the more remarkable that this variable has virtually been absent in the comparative analysis of the strategic behavior of political parties. In this regard, including voter transitions as a determinant of party behavior should be relevant to scholars far beyond the study of party positioning and for a wide range of analyses on policy making and democratic representation alike. Moreover, while we rely on a simple and straight-forward way of operationalizing voter transitions, future studies could investigate in more detail how transitions of different segments of the electorate (e.g., industrial workers) matter for party behavior. Another line of research should focus on how these strategic adjustments pay off electorally.

\section{SUPPLEMENTARY MATERIALS}

To view supplementary material for this article, please visit http://dx.doi.org/10.1017/S0003055420000155.

Replication materials can be found on Dataverse at: https://doi.org/10.7910/DVN/HULLNG.

\section{REFERENCES}

Adams, James, Michael Clark, Lawrence Ezrow, and Garrett Glasgow. 2004. "Understanding Change and Stability in Party Ideologies: Do Parties Respond to Public Opinion or to Past Election Results?" British Journal of Political Science 34 (4): 589-610.

Adams, James, and Zeynep Somer-Topcu. 2009. "Policy Adjustment by Parties in Response to Rival Parties' Policy Shifts: Spatial Theory and the Dynamics of Party Competition in Twenty-Five Post-War Democracies." British Journal of Political Science 39 (4): $825-46$.

Böhmelt, Tobias, Lawrence Ezrow, Roni Lehrer, and Hugh Ward. 2016. "Party Policy Diffusion." American Political Science Review 110 (02): 397-410.

Budge, Ian. 1994. "A New Spatial Theory of Party Competition: Uncertainty, Ideology and Policy Equilibria Viewed Comparatively and Temporally." British Journal of Political Science 24 (4): 443-67. 
Ezrow, Lawrence, Catherine E. de Vries, Marco R. Steenbergen, and Erica E. Edwards. 2011. "Mean Voter Representation and Partisan Constituency Representation: Do Parties Respond to the Mean Voter Position or to Their Supporters?" Party Politics 17 (3): 275-301.

Fowler, James H., and Michael Laver. 2008. "A Tournament of Party Decision Rules." Journal of Conflict Resolution 52 (1): 68-92.

Laver, Michael. 2005. "Policy and the Dynamics of Political Competition." American Political Science Review 99 (2): 263-281.

Lowe, Will, Kenneth Benoit, Slava Mikhaylov, and Michael Laver. 2011. "Scaling Policy Preferences from Coded Political Texts." Legislative Studies Quarterly 36 (1): 123-55.
Somer-Topcu, Zeynep. 2009. "Timely Decisions: The Effects of Past National Elections on Party Policy Change." Journal of Politics 71 (01): 238-48.

Volkens, Andrea, Pola Lehmann, Nicolas Merz, Sven Regel, and Annika Werner. 2017. The Manifesto Data Collection. Manifesto Project (MRG/CMP/MARPOR). Berlin: Wissenschaftszentrum Berlin für Sozialforschung (WZB).

Williams, Laron K., and Guy D. Whitten. 2015. "Don't Stand So Close to Me: Spatial Contagion Effects and Party Competition." American Journal of Political Science 59 (2): 309-25. 